\title{
Vegetative growth response of young olive trees (Olea europaea L., cv. Arbequina) to soil salinity and waterlogging
}

\author{
R. Aragüés ${ }^{1}$, J. Puy \& D. Isidoro
}

Servicio de Investigación Agroalimentaria-Diputación General de Aragón (DGA) y Laboratorio de Agronomía y Medio Ambiente (DGA-CSIC), Ap. 727, 50080 Zaragoza (Spain)

${ }^{1}$ Corresponding author

Key words: hypoxia, Olea europaea, salinity tolerance, trunk diameter, waterlogging, water table depth

\section{Abstract}

High-density olive orchards are increasing around the world, many of which may be potentially affected by salinity and waterlogging (hypoxia), two important stresses common in irrigated fields in arid and semi-arid climates. However, the response of olive to these stresses under field conditions is not well established. Therefore, our objective was to evaluate the vegetative growth response of young olive trees (Olea europaea L., cv. Arbequina) grown in a spatially-variable waterlogged, saline-sodic field. We monitored the growth in trunk diameter of 341 three-year's old olives between September 1999 and September 2000. Field contour maps were developed delineating soil salinity (ECa), relative ground elevation (RGE) and water table depth (WTD). Soil samples were also collected and analyzed for ECe and SARe in order to characterize the salinity and sodicity profiles and develop the ECa-ECe calibration equation. The infiltration rate (IR) of the crusted and uncrusted soil and the penetration resistance (PR) were also measured. The field was characterized by spatially variable ECe ( 2 to $15 \mathrm{dS} \mathrm{m}^{-1}$ ), SARe (3 to 40$)$, RGE (-4 to $\left.+4 \mathrm{~cm}\right)$ and WTD $\left(0.5\right.$ to $1.9 \mathrm{~m}$, with corresponding ground water EC values between 12 and $\left.6 \mathrm{dS} \mathrm{m}^{-1}\right)$. Steadystate IR of crusted soil was only $7 \%$ of the uncrusted soil. Since the field was heavily irrigated by 
flooding, waterlogging conditions were related to low RGE values. Soil salinity was negatively correlated $\left(\mathrm{R}^{2}=0.83, \mathrm{P}<0.001\right)$ with $\mathrm{RGE}$ (ponded water) and WTD (upward flux), due to the evapo-concentration of water and salts at the soil surface. Thus, inverted salinity profiles developed in high salinity areas. Fifty five percent of the olives were dead 3.5 years after planted, and most of them were located in areas of high ECe $\left(>10 \mathrm{dS} \mathrm{m}^{-1}\right)$, low RGE $(<-1.5 \mathrm{~cm})$ and low WTD $(<1.2$ $\mathrm{m})$. The surviving trees had vegetative salinity tolerance values of ECe threshold $=4 \mathrm{dS} \mathrm{m}^{-1}$ and slope $=-12 \%$ (i.e., percent decline per unit increase in ECe above the treshold), indicating that the Arbequina olive is moderately tolerant to salinity. The RGE and WTD thresholds for olive's survival were $>0.1 \mathrm{~cm}$ and $>1.6 \mathrm{~m}$, respectively. Thus, very small changes in ground elevation had a significant effect on olive's survival or death. The coupled effects of salinity and waterlogging (hypoxia) stresses were most detrimental for olive's growth. 


\section{Introduction}

Over 9 million hectares of the world's surface are planted with olives, $98 \%$ of which are grown in the Mediterranean basin alone. In terms of olive oil, the world's production is around 2.2 million tons, and the European Union (EU) produces $75 \%$ of it. Within EU, Spain is the first producer with $50 \%$ of total, followed by Italy (24\%) and Greece (22\%) (Barranco et al., 2001). These figures indicate the importance of olive production in the Mediterranean area, particularly Spain.

In the last decade, irrigated olive orchards have steadily increased in Spain and elsewhere. In particular, high-density plantations ( $>250$ trees/ha) have rapidly expanded in the middle Ebro river basin (Spain), and Aragón is at present the largest area in the world ( $>2300$ ha) with very highdensity (> 600 trees/ha) irrigated olive orchards (JL Espada, personal communication).

Although the potential yields achievable in these intensive plantations are high, they could be impaired by stresses associated with salt-, sodium- and waterlog-affected soils in this semiarid area (Herrero and Aragüés, 1988). Salinity depresses crop growth due to a decrease in the osmotic potential of the soil solution and by the presence of potentially toxic ions (i.e. $\mathrm{Na}$ and $\mathrm{Cl}$ ). Sodicity, besides the $\mathrm{Na}$ toxic effect, indirectly influences crop growth by damaging soil structure, and waterlogging causes oxygen deficits that injure the roots and shoots of crops. Although there are few data on the combined effects of salinity and waterlogging stresses on crops, Barrett-Lennard (2003) concluded that waterlogging under saline conditions increased leaf senescence and inhibited the ability of the roots to exclude salts, so that the concentrations of chloride and/or sodium substantially increased in the leaves or shoots of all the 24 plant species tested except rice (olive was not included in his work).

The real impact of these stresses on olive yield is uncertain, since the corresponding tolerance parameters have not yet been quantitatively established under field conditions. Olive is qualitatively classified as moderately tolerant to salinity (threshold electrical conductivity of the soil saturation extract, ECe $=3-6 \mathrm{dS} \mathrm{m}^{-1}$; Maas and Hoffman, 1977) and sodicity (threshold sodium adsorption ratio of the soil saturation extract, $\mathrm{SARe}<9$; Freeman et al, 1994), whereas it is 
qualified as sensitive to hypoxia conditions (Barranco et al., 2001). Field studies performed under the appropriate monitoring of these variables are scarce or non-existent, so that the response of olive to the combined salinity, sodicity and waterlogging stresses is unknown.

The objectives of this study are (i) to establish the relationships between various soil and hydrological characteristics of the field site (i.e., salinity, sodicity, waterlogging and groundwater depth), and (ii) to determine the vegetative growth response of young olive trees grown in this waterlogged, saline-sodic field.

\section{Materials and methods}

The $2000 \mathrm{~m}^{2}$ field under study is part of the Agro-Callén farm, located in sector V of the Flumen irrigation district (middle Ebro Valley, Aragón, Spain). The climate is characterized by mean annual temperature of $15.3^{\circ} \mathrm{C}, 434 \mathrm{~mm}$ of precipitation, and reference evapotranspiration of $1188 \mathrm{~mm}$. The Callén soil is classified as Typic Xerofluvent (Soil Survey Staff, 1999).

In spring 1997 semi-hardwood cuttings of the cv. Arbequina were planted with an intra-row distance of $1.8 \mathrm{~m}$ and an inter-row distance of $4 \mathrm{~m}$ (i.e., very high-density orchard with 1400 trees/ha). An area of $2000 \mathrm{~m}^{2}$ was selected within the field, comprising five rows of trees with a length each of $125 \mathrm{~m}$. The trunk diameter of each of the 341 trees planted in this area was measured on 10 September 1999 and 13 September 2000 with a digital electronic calliper placed over a permanent-ink mark located at about $20 \mathrm{~cm}$ from the trunk base. The difference in trunk diameter between these dates will be referred as the "one-year growth trunk diameter" ( $\Delta$ trunk diameter, $\Delta \mathrm{TD})$. These measurements were used to delineate the map of $\Delta \mathrm{TD}$ contour lines obtained through interpolation by kriging using the Surfer program (Golden Software, Inc.).

The field was flood-irrigated three times during the irrigation season (April to September 2000). The Flumen canal irrigation water is of excellent quality for crop production ( $\mathrm{EC}<0.4 \mathrm{dS} \mathrm{m}^{-}$ ${ }^{1}$, SAR $<1$ ), but its low salinity causes soil crusting and water penetration problems in this salinesodic soil. 


\section{Soil salinity and sodicity}

The apparent soil salinity (ECa) was measured in August 1999 and September 2000 with a Geonics EM38 sensor placed on the ground in its horizontal (h) dipole position. These readings will be referred as ECa-h $\left(\mathrm{dS} \mathrm{m}^{-1}\right)$. The 1999 readings were made every $10 \mathrm{~m}$ along two transects parallel and in-between the tree lines (i.e., 38 points of measurement. The 2000 readings were made similarly every $5 \mathrm{~m}$ along four transects (i.e., 101 points of measurement). The EM38 was not placed in the tree lines because the olives were tutored with a metal rod that will interfere the readings. The measurements were performed several days after an irrigation (i.e., at relatively high soil water contents), as soon as the field was trafficable. Soil temperatures were measured at depths of $20 \mathrm{~cm}$ and $40 \mathrm{~cm}$ with a digital soil thermometer in order to convert the ECa-h readings to a reference temperature of $25^{\circ} \mathrm{C}$.

The ECa-h $\left(\mathrm{dS} \mathrm{m}^{-1}\right)$ values measured in 1999 and 2000 were similar (mean $=1.88$ in 1999 and 1.83 in 2000; median $=2.03$ in 1999 and 1.96 in 2000; $C V=46 \%$ in 1999 and $41 \%$ in 2000 ). Since the number of reading points was higher in 2000, we selected them for developing the maps that delineate the ECa-h contour lines obtained through interpolation by kriging using the Surfer program. The ECa-h in each tree coordinate was estimated from this map. These estimates were used for establishing the response of $\Delta \mathrm{TD}$ to soil salinity.

Eight locations covering the studied area were selected in June 1999 for sampling the soil at $25-\mathrm{cm}$ depth increments to a depth of $150 \mathrm{~cm}$. Another 18 points covering the full range of the ECa$\mathrm{h}$ measurements were selected in September 2000 and EM38 readings and 0-50 cm depth soil samples were taken in each point. The soil samples were air-dried, ground and sieved $(<2 \mathrm{~mm})$, and the salinity (ECe) and sodicity (SARe) were measured in the soil saturation extract. The 1999 samples were used for delineating the salinity and sodicity profiles, whereas the 2000 samples were used for the establishment of the relations between ECe, SARe and ECa-h. 


\section{Infiltration rate and penetration resistance}

The infiltration rate (IR) of water into the soil was measured in September 1999 in the middle of the study area $(X=10 \mathrm{~m})$ at five points located at distances of $\mathrm{Y}=-5,10,15,40$, and $70 \mathrm{~m}$. The measurements were made with an automatic infiltrometer (Amézketa et al., 2002) which records the water infiltrated in a single Muntz ring, driven in the soil to a depth of $5 \mathrm{~cm}$, every $10 \mathrm{~min}$. Since the soil was crusted at the time of measurement, additional rings were driven in the soil close to the previous points after removal of the crusted layer (i.e., about $2 \mathrm{~cm}$ surface soil). In this way, we characterized the mean IR of the uncrusted and crusted soils.

The penetration resistance of the $0-80 \mathrm{~cm}$ soil profile was measured with an Eijkelkamp Stiboka penetrograph in September 1999 in the middle of the study area $(\mathrm{X}=10 \mathrm{~m})$ in fifteen points along the $\mathrm{Y}$ direction. A minimum of five readings were taken in each point, and an average penetration resistance profile was visually delineated. From these profiles, we obtained the maximum penetration resistances for the soil depth intervals of $0-25,25-50$ and $50-75 \mathrm{~cm}$. Gravimetric water contents were also measured at each soil depth interval.

\section{Ground elevation and salinity and depth of the water table}

The ground elevation was measured with a digital altimeter in September 2000 every $5 \mathrm{~m}$ in four transects located in-between each pair of tree lines along the Y direction for a total of 102 readings. Each elevation was subtracted from the mean elevation to obtain the map of relative elevation contour lines through interpolation by kriging using the Surfer program. Thus, positive (negative) numbers indicate points above (below) the mean. Therefore, negative numbers correspond to potential waterlogged areas developed after a precipitation or irrigation event. The relative ground elevation (RGE) in each tree coordinate was estimated from the contour map. These estimates were used for establishing the response of $\triangle \mathrm{TD}$ to potential waterlogging conditions.

The depth of the water table from the ground was measured in four evenly-spaced dates along the April to September 2000 irrigation season in nine observation wells (2-m long perforated 
PVC tubes with gravel at the bottom) distributed in a regular grid within the field. The average water table depth (WTD) in each well was used for delineating the contour map obtained through interpolation by kriging using the Surfer program. After measuring WTD in each well, the EC was determined in the field. During the study period, the EC varied between 10 and $12 \mathrm{dS} \mathrm{m}^{-1}$ at $\mathrm{Y}$ distances between -10 and $40 \mathrm{~m}$, and between 6 and $7 \mathrm{dS} \mathrm{m}^{-1}$ at $\mathrm{Y}$ distances greater than $80 \mathrm{~m}$. In one occasion, the water from the observation well located at $(X, Y)=(0,0)$ was fully extracted and after its replenishment a water sample was taken, brought to the laboratory and analyzed for EC (11.6 dS m $\left.{ }^{-1}\right), \mathrm{pH}(8.0), \mathrm{Na}\left(108 \mathrm{meq}^{-1}\right), \mathrm{Ca}\left(0.4 \mathrm{meq}^{-1}\right), \mathrm{Mg}\left(6.6 \mathrm{meq}^{-1}\right), \mathrm{SAR}(58)$ and $\mathrm{Cl}(77$ meq $\left.1^{-1}\right)$.

\section{Results and discussion}

The contour maps depicted in Fig. 1 show that the study area was characterized by a gradient in the Y direction along which soil salinity and sodicity decreased, and ground elevation and water table depth increased with increasing Y distances from the beginning of the field. The contour map of the seasonal average water table depth (Fig. 1D) indicates that the direction of the groundwater flow was in the $\mathrm{Y}$ direction. This flow most probably originated from the lateral seepage of a 2-ha ponded rice field located at $\mathrm{Y}=-20 \mathrm{~m}$.

The high soil (Fig. 1C) and water table (EC around 10-12 $\mathrm{dS} \mathrm{m}^{-1}$ ) salinities in the first 40 to $60 \mathrm{~m}$ of the field were attributed to the existence of saliferous Miocenic underlying strata coupled to the upward capillary flow of water from the shallow water tables and the subsequent evapoconcentration of water and salts at the soil surface. Thus, for a silty clay loam texture as that of the Callén soil, the normalized maximum upward flux will be $<2.5 \mathrm{~mm} \mathrm{day}^{-1}$ for a water table depth $>$ $1.6 \mathrm{~m}$, but could increase up to $10 \mathrm{~mm} \mathrm{day}^{-1}$ for a water table depth $<1 \mathrm{~m}$ (Kruse et al., 1990).

This upward flux also explains the inverted soil salinity profiles (i.e., ECe increasing towards the soil surface) observed in points of high salinity, as compared to the uniform profiles observed in points of low salinity (Fig. 2). The parallelism between the salinity (ECe) and the 
sodicity (SARe) profiles, the high SAR's $(>15)$ measured in most soil samples, and the significant correlation $(\mathrm{P}<0.001)$ between ECe and SARe (Fig. 3A) are consistent with the high sodium contents of some of the lutites present in the Monegros area (Tedeschi et al., 2001), and with the selective precipitation of calcium salts during the evaporative salinization of the high sodium (SAR $=58$ ) and shallow water tables present in part of the study field.

The illitic character of the Callén soil, its high sodicity and the low salinity of the irrigation water $\left(\mathrm{EC}<0.4 \mathrm{dS} \mathrm{m}^{-1}\right)$ impaired clay dispersion, soil sealing and severe crusting upon drying. Thus, the infiltration of water in the crusted soil was very low (average final infiltration rate $=1.3$ $\mathrm{mm} \mathrm{h}^{-1} ; \mathrm{CV}=46 \%$ ), as compared to that of the uncrusted soil (average final infiltration rate $=18.4$ $\mathrm{mm} \mathrm{h}^{-1} ; \mathrm{CV}=75 \%$ ) (Fig. 4). Soil crusting, besides limiting the infiltration of water into soil, favours the evaporation of the water standing over the ground thus increasing soil-surface salinization (Sumner and Stewart, 1992), and limits the gas exchange between soil and atmosphere thus inducing poor soil aeration (Drew, 1983).

The maximum penetration resistance of the $0-75 \mathrm{~cm}$ soil profile was very high, especially at Y distances between 25 and $55 \mathrm{~m}$ (Fig. 5). The values were highest at $0-25 \mathrm{~cm}\left(\right.$ mean $=365 \mathrm{~N} \mathrm{~cm}^{-2}$, $\mathrm{CV}=17 \%)$ and decreased somewhat with soil depth (mean $=333 \mathrm{~N} \mathrm{~cm}^{-2}, \mathrm{CV}=25 \%$ at $25-50 \mathrm{~cm}$, and $299 \mathrm{~N} \mathrm{~cm}^{-2}, \mathrm{CV}=25 \%$ at $50-75 \mathrm{~cm}$ ). Since gravimetric water contents were relatively high and rather constant in all sites and depths (average $=21 \%, \mathrm{CV}=12 \%$ ), the high penetration resistance values were attributed to the Callén soil physical and chemical characteristics and to soil compaction provoked by the traffic over relatively wet soils. Figure 5 shows that all the maximum penetration resistance measurements were $>200 \mathrm{~N} \mathrm{~cm}^{-2}$, a value considered critical of mechanical or restrictive impedance for root growth (Sumner and Stewart, 1992). In addition, Barrett-Lennard (2003) indicated that high soil penetration resistances and low soil infiltration rates favours hypoxia conditions in the soil.

The ground elevation showed a gradient along the Y direction, so that the first $60-80 \mathrm{~m}$ were depressed as compared to the last 40-60 $\mathrm{m}$ of the field (Fig. 1B and Fig. 6). Since the field was 
flood-irrigated in the $\mathrm{Y}$ direction from an elevated concrete ditch located at $\mathrm{Y}=-10 \mathrm{~m}$, high water application depths were needed to fully irrigate the field. In consequence, irrigation uniformity was rather poor and, coupled to the low infiltration rate of the crusted soil, provoked waterlogging in the depressed areas of the field, potentially impairing oxygen deficiency and injury to olive's roots and shoots.

Soil salinity (ECe)-relative ground elevation (RGE)-water table depth (WTD) relationships

The ECa-h readings taken with the EM38 sensor were converted into ECe by means of the equation given in Fig. 3C. ECe and relative ground elevation (RGE) were linearly and negatively correlated $(\mathrm{P}<0.001)$ (Fig. 7A). This negative correlation suggests that most of the water standing in the ground depressions evaporated due to the low infiltration rate of the Callen crusted soil (Fig. 4), thus increasing soil salinity. It is interesting to note that minor changes in ground elevation produced large variations in soil salinity. It is possible that the permanent landscape elevations had a larger influence on salinity patterns in the field than the more transient water table depths. This salinity increase in the ponded areas is opposite to that found in high-infiltration, furrow-irrigated fields where the ponded areas had lower salinity values than the raised areas (Rhoades et al., 1997).

Soil salinity was high and relatively constant for water table depths shallower than 1.2 to 1.5 $\mathrm{m}$ (depending on the transect $\mathrm{X}=0$ to $16 \mathrm{~m}$ ) (Fig. 7B). The apparent ECe decreases for $\mathrm{WTD}<0.9$ $\mathrm{m}$ were attributed to higher RGE in the first $20 \mathrm{~m}$ of the field, the area where these shallow water table depths were present (Fig. 1). WTD sharply decreased with increasing depths above 1.2-1.5 m, a threshold range that agrees with those given by Kruse et al. (1990). Thus, soil salinity depended on the coupled effects of the maximum upward flow of water (i.e., the water table depth will be the limiting evaporation factor for depths greater than around 1.2-1.5 m) and the maximum evaporation from the soil surface (i.e., the potential evapotranspiration will be the limiting evaporation factor for depths lower than around 1.2-1.5 m 
Based on these results, a multiple linear regression of ECe on WTD and RGE was performed using the 341 estimated values in each tree coordinate:

$$
\operatorname{ECe}\left(\mathrm{dS} \mathrm{m} \mathrm{m}^{-1}\right)=-2.6 \operatorname{RGE}(\mathrm{cm})-2.3 \operatorname{WTD}(\mathrm{m})+10.3
$$

This equation has an $\mathrm{R}^{2}=0.827$ (significant at $\mathrm{P}<0.001$ ) and a standard error of the ECe estimate $=$ $1.7 \mathrm{dS} \mathrm{m}^{-1}$ indicating that, for the field and time period studied, soil salinity may be consistently estimated from these variables.

Growth of the olive trees as related to soil salinity, relative ground elevation and water table depth

\section{Qualitative statistical analysis}

Fifty one percent of the olives planted in spring-1997 were dead in September 1999 (i.e., 2.5 years after planting). An additional 4\% died in the following year (i.e., between September 1999 and September 2000). As expected, most dead trees were located in areas of lower ground elevation, higher soil salinity and sodicity and more saline and shallower water table depths (Fig. 1).

The one-year growth trunk diameter $(\Delta \mathrm{TD})$ of the surviving trees was highly variable as a result of the combination of salinity, sodicity and waterlogging stresses and its variability in the study field, so that classical growth-response models could not be rigorously fitted to the observations. Nevertheless, the Maas and Hoffman (1977) model was fitted to the " $\Delta$ TD-ECe" observations using the upper-envelope eye-fitting approach. The rational of this approach is that, for a given soil salinity value, only the maximum $\Delta \mathrm{TD}$ value is fitted to the model because the rest of $\Delta \mathrm{TD}$ values lower than the maximum imply that they are negatively affected by other stresses besides salinity.

Figure $8 \mathrm{~A}$ shows that (i) a maximum $\Delta \mathrm{TD}$ of around $2.3 \mathrm{~cm}$ was obtained for the lowest ECe values, (ii) above an ECe-threshold value of around $4 \mathrm{dS} \mathrm{m}^{-1}$ the growth of most trees declined with an slope of around -12\% (i.e., percent decline in $\triangle \mathrm{TD}$ per unit increase in ECe), and (iii) the Xintercept of the fitted line is around $12 \mathrm{dS} \mathrm{m}^{-1}$ (i.e., $\mathrm{ECe}_{\mathrm{o}}$ at which $\Delta \mathrm{TD}=0$ ). The dotted lines 
depicted in Fig. 8A enveloped $90 \%$ of the surviving trees $(\Delta \mathrm{TD}>0)$. The maximum trunk diameter growth of $2.3 \mathrm{~cm}$ year $^{-1}$ is consistent with that obtained for 3 years-old Arbequina trees grown in non-saline soils. Although these salinity tolerance values should be taken as a rough approximation, they indicate that the young Arbequina olive was moderately tolerant to soil salinity. This ranking in olive's salinity tolerance has been previously reported (Gucci and Tattini, 1997)

The scattering of the $\triangle \mathrm{TD}$-ECe observations shown in Fig. $8 \mathrm{~A}$ indicate that olive's response also depended on other stresses. Thus, deleting the observations with $\Delta \mathrm{TD}=0$, a significant $(\mathrm{P}<0.001)$ and positive correlation was found between $\Delta \mathrm{TD}$ and relative ground elevation (RGE) (Fig. 8B). In consequence, olive's growth decreased with waterlogging conditions in the soil. Based on the observations shown in Fig. 8B, it was apparent that below a RGE threshold of around - 1.5 $\mathrm{cm}$, most trees were dead.

$\Delta \mathrm{TD}$ was also regressed against RGE for two different sets of data consisting, respectively, in observations with soil salinity values below and above the previously obtained ECe-threshold of $4 \mathrm{dS} \mathrm{m}^{-1}$. For the first data set $\left(\mathrm{ECe}<4 \mathrm{dS} \mathrm{m}^{-1}\right), \Delta \mathrm{TD}$ will basically depend on ground elevation since soil salinity is lower than its tolerance limit; for the second data set (ECe $>4 \mathrm{dS} \mathrm{m}^{-1}$ ), $\Delta \mathrm{TD}$ will depend both on ground elevation and soil salinity. Both regressions were significant $(\mathrm{P}<0.001)$, but the coefficients of regression were 0.39 (for ECe $>4 \mathrm{dS} \mathrm{m}^{-1}$ ) and 0.22 (for ECe $<4 \mathrm{dS} \mathrm{m}^{-1}$ ), indicating that olive's growth was more sensitive to waterlogging conditions under saline than under non-saline conditions. This result agrees with Barrett-Lennard (2003) in that the "salinitywaterlogging" interaction is most detrimental to crops.

Finally, Figure $8 \mathrm{C}$ shows that $\Delta \mathrm{TD}$ and water table depth (WTD) were not related, although most trees were dead in areas of the field with WTD $<1.3 \mathrm{~m}$, and only $10 \%$ of the trees survived at WTD between 1.3 and $1.5 \mathrm{~m}$. Thus, a value of around $1.3 \mathrm{~m}$ was selected as the threshold WTD for survival of olive's trees in the study field. 


\section{Quantitative statistical analysis}

The combined influence of the three explanatory variables (ECe, WTD and RGE) on the one-year growth trunk diameter $(\Delta \mathrm{TD})$ of olives was analyzed using three different approaches: (i) principal component analysis that combine the variables having the greatest influence on trees' survival or death, (ii) regression models that assume a zero olive's growth for given values of one of the variables or a combination of them, and (iii) conditional probabilities of trees' survival or death for certain ranges of the explanatory variables.

\section{(i) Principal component analysis}

The principal components analysis carried out on ECe, WTD and RGE shows that two components explained up to $97 \%$ of the variance of the three standardized variables. The observations presented a $\mathrm{V}$-shape scatter, with one arm corresponding roughly to surviving trees $(\Delta \mathrm{TD}>0)$ and the other arm (plus the upper part of the first arm) corresponding to dead trees $(\Delta \mathrm{TD}=0)$ (Fig. 9). Most of the living trees were consistently located along the direction of variation of the coupled ECe-RGE variables. As previously indicated, these two variables are negatively correlated (Fig. 7A) so that they have opposite projections on the plane. The dead trees were more dispersed, several of them were situated among the surviving trees, and they showed a higher variation in the WTD direction than in the ECe-RGE direction.

A cluster analysis using the Euclidean distance and the Ward aggregation method was performed on ECe, WTD and RGE, taking as variables the two first standardized principal components. Two groups were delineated that closely resembled the alive and dead trees (Fig. 9). This data classification was selected because it presents the highest ratio of the variance between the clusters to the total variance. Cluster 1 (dead trees, $\Delta \mathrm{TD}=0$; only 16 alive trees were located in this group) was characterized by relatively high ECe $\left(11.0 \mathrm{dS} \mathrm{m}^{-1}\right)$ and relatively low RGE (-1.6 $\mathrm{cm})$ and WTD $(1.2 \mathrm{~m})$ values. Cluster 2 (surviving trees, $\Delta \mathrm{TD}>0$; only 14 dead trees were located 
in this group) showed lower ECe $\left(4.1 \mathrm{dS} \mathrm{m}^{-1}\right)$ and higher RGE $(0.6 \mathrm{~cm})$ and WTD $(1.7 \mathrm{~m})$ values. These ECe, RGE and WTD values were consistent with those given in Fig. 8.

Within Cluster $1(\Delta \mathrm{TD}=0), \mathrm{ECe}, \mathrm{WTD}$ and RGE were not significantly correlated $(\mathrm{P}>$ 0.05) among them and, as expected since most $\Delta \mathrm{TD}$ values were zero, none of the explanatory variables were correlated with $\Delta \mathrm{TD}$. Within Cluster $2(\Delta \mathrm{TD}>0), \mathrm{ECe}, \mathrm{WTD}$ and RGE were significantly correlated $(\mathrm{P}<0.001)$ among them as well as with $\Delta \mathrm{TD}$.

This analysis confirms that the survival or death of the olive trees may be ascertained from ECe, RGE and WTD since, based on these variables, the trees were consistently grouped into two clusters $(\Delta \mathrm{TD}>0$ and $\Delta \mathrm{TD}=0)$.

\section{(ii) Regression analysis}

The objectives of the regression models were to estimate $\triangle \mathrm{TD}$ and the range of ECe, WTD and RGE values at which olives were alive or dead. Three models were selected in which the $\Delta T D$ estimates out of the growth range were set equal to zero, whereas the $\Delta \mathrm{TD}$ estimates within the growth range had to be positive. The $\Delta \mathrm{TD}$ estimates were forced to decrease to zero in the boundary of the growth range.

The first model regressed $\triangle \mathrm{TD}$ on the three explanatory variables assuming that the observations were linearly fitted when they were within a region delimited by a plane intersecting the ECe, WTD and RGE axis at $a, b$ and $c$, respectively, whereas $\Delta \mathrm{TD}=0$ outside this region:

$$
\begin{aligned}
& \Delta \mathrm{TD}=k(1-(\mathrm{ECe} / a+\mathrm{WTD} / b+\mathrm{RGE} / c)), \text { for }(\mathrm{ECe} / a+\mathrm{WTD} / b+\mathrm{RGE} / c)<1 \\
& \Delta \mathrm{TD}=0, \text { for }(\mathrm{ECe} / a+\mathrm{WTD} / b+\mathrm{RGE} / c)>1
\end{aligned}
$$

where $k$ stands for the value of $\Delta \mathrm{TD}$ when $\mathrm{ECe}=\mathrm{WTD}=\mathrm{RGE}=0$.

The parameters of the fitted model were: $a=11.9, b=-3.010^{13}, c=-7.8$ and $k=1.7$, with $\mathrm{R}^{2}=0.751$ (significant at $\mathrm{P}<0.001$ ) and $\mathrm{s}($ standard error of the estimate) $=0.39$. Although this model is conceptually consistent (i.e., $\Delta \mathrm{TD}$ increases with decreasing ECe and increasing WTD and 
RGE values), the $b$ intercept is orders of magnitude higher than the $a$ and $c$ intercepts, indicating that $\triangle \mathrm{TD}$ depends primarily on ECe and RGE. These results are consistent with those obtained in the principal component analysis, where the variation of the surviving trees was along the ECeRGE direction (Fig. 9).

The second model regressed $\triangle \mathrm{TD}$ on the two principal explanatory variables (ECe and RGE), and the boundary between the growth and no-growth ranges was set as a linear function of $\mathrm{ECe}$ and $\mathrm{RGE}(\mathrm{ECe} / a+\mathrm{RGE} / b=1)$ :

$$
\begin{aligned}
& \Delta \mathrm{TD}=k[1-(\mathrm{ECe} / a+\mathrm{RGE} / b)], \text { for }(\mathrm{ECe} / a+\mathrm{RGE} / b)<1 \\
& \Delta \mathrm{TD}=0, \text { for }(\mathrm{ECe} / a+\mathrm{RGE} / b)>1
\end{aligned}
$$

The adjusted parameters were $a=11.7, b=-8.9$ and $k=1.73$, with $\mathrm{R}^{2}=0.752$ and $\mathrm{s}=0.39$.

The weakest point of this model is that $\Delta \mathrm{TD}$ increases indefinitely with RGE. Nevertheless, this simpler model provides a fit as good as the previous model, is also conceptually consistent, and sets a relationship between ECe and RGE for the boundary among the olive's growing and nongrowing regions. Thus, based in the equation ECe/11.7 - RGE/8.9 = 1, the olive's growth limiting ECe values for the RGE range measured in the study field (roughly -3 to $+3 \mathrm{~cm}$ ) will be $7.8 \mathrm{dS} \mathrm{m}^{-1}$ (at $\mathrm{RGE}=-3 \mathrm{~cm}$ ) and $15.6 \mathrm{dS} \mathrm{m} \mathrm{m}^{-1}$ (at $\mathrm{RGE}=3 \mathrm{~cm}$ ) (Fig. 7A). Similarly, for the ECe-RGE observations falling over this line the limiting ECe values will be 8.5 (at RGE $=-2.5 \mathrm{~cm}$ ) and 11.0 $\mathrm{dS} \mathrm{m}^{-1}$ (at $\mathrm{RGE}=0.5 \mathrm{~cm}$ ). These results indicate, as previously reported, that under waterlogging conditions (negative RGE values) the growth of olives was more sensitive to salinity (i.e., the ECe tolerance limit for growth was lower) than under normal conditions (positive RGE values).

Since ECe and RGE are significantly correlated (Fig. 7A), a third regression model was proposed with only ECe as the explanatory variable. This model is based on the assumption that $\Delta \mathrm{TD}$ is a linear function of ECe only within the region with WTD higher than a given limit $\left(\mathrm{WTD}_{\mathrm{o}}\right)$ and ECe lower than a given limit $\left(\mathrm{ECe}_{\mathrm{o}}\right)$, and that $\triangle \mathrm{TD}$ is zero outside this region (Fig. $\left.7 \mathrm{~B}\right)$ :

$$
\begin{aligned}
& \Delta \mathrm{TD}=c\left(\mathrm{ECe}_{\mathrm{o}}-\mathrm{ECe}\right) / \mathrm{ECe}_{\mathrm{o}}, \text { for } \mathrm{ECe}<\mathrm{ECe}_{\mathrm{o}} \text { and } \mathrm{WTD}>\mathrm{WTD}_{\mathrm{o}} \\
& \Delta \mathrm{TD}=0, \text { for } \mathrm{ECe}>\mathrm{ECe}_{\mathrm{o}} \text { or } \mathrm{WTD}<\mathrm{WTD}_{\mathrm{o}}
\end{aligned}
$$


The adjusted parameters were $\mathrm{WTD}_{\mathrm{o}}=1.4 \mathrm{~m}, \mathrm{EC}_{\mathrm{o}}=10.0 \mathrm{dS} \mathrm{m} \mathrm{m}^{-1}$ and $c=2.1$, with $\mathrm{R}^{2}=0.752$ and $\mathrm{s}=0.39$. A problem with this model is that there is a jump in the estimation function for WTD values slightly higher and lower than WTDo. Nevertheless, this model allows for the estimation of olive's growth $(\Delta \mathrm{TD})$ as a function of only one explanatory variable (ECe), and provides the limiting $\mathrm{ECe}_{\mathrm{o}}\left(10 \mathrm{dS} \mathrm{m} \mathrm{m}^{-1}\right)$ and $\mathrm{WTD}_{\mathrm{o}}(1.4 \mathrm{~m})$ values for the growth of olive trees in the study field. The equation of this model for $\mathrm{ECe}<10 \mathrm{dS} \mathrm{m}^{-1}$ and WTD $>1.4 \mathrm{~m}$ is: $\Delta \mathrm{TD}=2.1-0.21$ $\mathrm{ECe}$, so that it predicts a maximum $\Delta \mathrm{TD}=2.1 \mathrm{~cm}$ for $\mathrm{ECe}=0$, and a percent yield decline per unit increase in ECe of - 10\%. These values are close to those given in Fig 8 (maximum $\Delta \mathrm{TD}=2.3 \mathrm{~cm}$; slope $\left.=-12 \% ; \mathrm{ECe}_{\mathrm{o}}=12 \mathrm{dS} \mathrm{m}{ }^{-1} ; \mathrm{WTD}_{\text {threshold }}=1.3\right)$.

\section{(iii) Conditional probability analysis}

The objective of this analysis was to establish the limits of the explanatory variables (ECe, RGE, WTD) for the probability of survival $[\mathrm{P}(\Delta \mathrm{TD}>0)]$ or death $[\mathrm{P}(\Delta \mathrm{TD}=0)]$ of the olive trees grown in the study field.

In terms of soil salinity (ECe), the following probabilities were calculated: $\mathrm{P}(\Delta \mathrm{TD}>0$ / $\mathrm{ECe}<\mathrm{ECe}_{\mathrm{o}}$ ) (i.e., probability for a tree to survive provided $\mathrm{ECe}$ is lower than a given value $\mathrm{ECe}_{\mathrm{o}}$ ), and $\mathrm{P}\left(\Delta \mathrm{TD}=0 / \mathrm{ECe}>\mathrm{ECe}_{\mathrm{o}}\right)$ (i.e., probability for a tree to die provided $\mathrm{ECe}$ is higher than a given value $\mathrm{ECe}_{\mathrm{o}}$ ). The probabilities were estimated as the ratio of trees surviving (or dying) in a given range of ECe (below or above $\mathrm{ECe}_{\mathrm{o}}$ ) to the total number of trees in that ECe range. These probabilities $(\mathrm{P})$ were plotted against $\mathrm{ECe}_{\mathrm{o}}$. The most desirable feature of this plot will be the existence of clear probability jumps at $\mathrm{P}$ values close to 1 for a given $\mathrm{ECe}_{\mathrm{o}}$. In this approach, $\mathrm{ECe}_{\mathrm{o}}$ will be regarded as the threshold limit below (above) which trees will survive (die). Figure $10 \mathrm{~A}$ shows that $\mathrm{P}(\Delta \mathrm{TD}=0)$ steadily increased with increasing $\mathrm{ECe}_{\mathrm{o}}$ values, reaching a $\mathrm{P}$ plateau of around $0.9-0.95$ at $\mathrm{ECe}_{\mathrm{o}}>8.5 \mathrm{dS} \mathrm{m}^{-1}$ (i.e., 90 to $95 \%$ of the trees will die above this ECe threshold. In contrast, $\mathrm{P}(\Delta \mathrm{TD}>0)$ increased with decreasing $\mathrm{ECe}_{\mathrm{o}}$ values, reaching a $\mathrm{P}$ plateau of 0.96 for $\mathrm{ECe}_{\mathrm{o}}$ $<5.1 \mathrm{dS} \mathrm{m}^{-1}$, below which tree survival was independent of soil salinity. 
In terms of soil waterlogging (RGE), Fig. $10 \mathrm{~B}$ shows that $\mathrm{P}(\Delta \mathrm{TD}>0)$ increased with increasing $\mathrm{RGE}_{\mathrm{o}}$ values up to a value of around $0.14 \mathrm{~cm}$, above which $\mathrm{P}$ stabilized at about 0.95 and was independent of ground elevation. Thus, most trees will survive above an $\mathrm{RGE}_{\mathrm{o}}$ threshold of $0.14 \mathrm{~cm}$. In contrast, $\mathrm{P}(\Delta \mathrm{TD}=0)$ steadily increased with decreasing $\mathrm{RGE}_{\mathrm{o}}$ values, so that $95 \%$ of the trees will die for $\mathrm{RGE}_{\mathrm{o}}<-1.7 \mathrm{~cm}$. It is interesting to note that the $\mathrm{P}(\Delta \mathrm{TD}=0)$ curves for both $\mathrm{ECe}_{\mathrm{o}}$ and $\mathrm{RGE}_{\mathrm{o}}$ did not show clear inflexion points, suggesting that the effect of soil salinity and waterlogging on trees' death took place in a steady manner along a wide range of these variables.

Finally, in terms of water table depth (WTD), Fig. $10 \mathrm{C}$ shows that $\mathrm{P}(\Delta \mathrm{TD}>0)$ slowly increased with increasing $\mathrm{WTD}_{\mathrm{o}}$ up to $1.5 \mathrm{~m}$, sharply increased between 1.5 and $1.65 \mathrm{~m}$, and leveled off at $\mathrm{P}>0.95$ for $\mathrm{WTD}_{\mathrm{o}}>1.65 \mathrm{~m}$. Thus, this $\mathrm{WTD}_{\mathrm{o}}$ of $1.65 \mathrm{~m}$ could be regarded as the limit above which trees' survival was high and independent of water table depth. The $\mathrm{P}(\Delta \mathrm{TD}=0)$ increased with decreasing $\mathrm{WTD}_{\mathrm{o}}$, reaching a $\mathrm{P}=0.95$ plateau at $\mathrm{WTD}_{\mathrm{o}}=1.2 \mathrm{~m}$. In consequence, this value was considered as the threshold limit below which most trees will die.

\section{Conclusions}

The $2000 \mathrm{~m}^{2}$ olive's orchard was highly variable in terms of soil salinity, sodicity, infiltration rate, penetration resistance, ground elevation, and depth and salinity of the water table. The depressed areas in the field (i.e., low relative ground elevation values over the mean) induced severe waterlogging (hypoxia) due to an improper management of flooding irrigation coupled to the almost impermeable surface-crusted soil. Soil salinity (ECe) and sodicity SARe) were highest in areas with shallow water table depths (WTD) and low relative ground elevations (RGE), due to the evapoconcentration of water and salts at the soil surface (i.e., ECe was negatively correlated $(\mathrm{P}<0.001)$ with RGE and WTD).

Fifty five percent of the 341 monitored olives were dead 3.5 years after planted, and most of them were located in areas of high ECe $\left(>10 \mathrm{dS} \mathrm{m}^{-1}\right)$, low RGE $(<-1.5 \mathrm{~cm})$ and low WTD $(<1.2$ $\mathrm{m})$. The corresponding threshold values for surviving trees were ECe $<4.1 \mathrm{dS} \mathrm{m}{ }^{-1}$, slope $=-12 \%$, 
RGE $>0.1 \mathrm{~cm}$ and WTD $>1.6 \mathrm{~m}$. These threshold values are useful for delimiting the tolerance of Arbequina olives to salinity and waterlogging (hypoxia) stresses, but the effects of the ECe, RGE and WTD interactions on olive's growth merits further work.

Our results indicate that the coupling effects of salinity and waterlogging (hypoxia) stresses were most detrimental to olive's survival and growth, and that salinity tolerance decreased under waterlogged conditions. Since the leaching of salts in this saline-sodic field is restricted by its low soil infiltration rate (final infiltration rate $=1.3 \mathrm{~mm} \mathrm{~h}^{-1}$ ), high penetration resistance (soil profile maximum penetration $>200 \mathrm{~N} \mathrm{~cm}^{-2}$ ) and shallow water table, some practical solutions for reducing the salinity and waterlogging stresses could be (i) planting of olives in raised beds, (ii) mulching to minimize soil surface evapo-concentration, and (iii) installation of interceptor drains to limit groundwater flows towards the study field.

\section{Acknowledgments}

This study was partially supported by INIA (Instituto Nacional de Investigación y Tecnología Agraria y Alimentaria, Spain). We kindly acknowledge the technical assistance of Mr. M. Izquierdo, Mr. J. Gaudó, Ms. D. Naval and Ms. R. Gómez, and the collaboration of Mr. J. M. Viñales, owner of the farm.

We want to honor the memory of the co-author Mr. J. Puy, who died of a fatal accident in November 2002.

\section{References}

Amézketa E, Gazol R and Aragüés R 2002 Desarrollo de un infiltrómetro automático y su aplicación en campo. Invest. Agr.: Prod. Prot. Veg. 17, 131-142.

Barranco D, Fernández-Escobar R and Rallo L 2001 El Cultivo del Olivo. Mundi-Prensa, Madrid, Spain. 724 p. 
Barrett-Lennard E G 2003 The interaction between waterlogging and salinity in higher plants: causes, consequences and implications. Plant Soil 253, 35-54.

Drew M C 1983 Plant injury and adaptation to oxygen deficiency in the root environment: A review. Plant Soil 75, 179-199.

Freeman M, Uriu K and Hartmann H T 1994 Diagnosing and correcting nutrient problems. In Olive Production Manual. Eds. L Ferguson, G S Sibbett and G C Martin. Pp 77-86. Univ. California, Div. Agric. and Nat. Resour., publication n 3353.

Gucci R and Tattini M 1997 Salinity tolerance in Olive. Hortic. Rev. 21, chapter 6. J. Janick ed. John Wiley \& Sons, Inc., New York., 177-214.

Herrero J and Aragüés R 1988 Suelos afectados por salinidad en Aragón. Surcos de Aragón 9, 5-10.

Kruse E G, Willardson L and Ayars J 1990 On farm irrigation and drainage practices. In Agricultural Salinity Assessment and Management. Ed. K K Tanji. pp 349-371. Amer. Soc. Civil Eng. Manual n ${ }^{\circ} 71$, New York.

Maas E V and Hoffman G J 1977 Crop salt tolerance-current assessment. J. Irrig. Drainage Div. 103, 115-134.

Rhoades J D, Lesch S M, Lemert R D and Alves W J 1997 Assessing irrigation-drainage-salinity management using spatially referenced salinity measurements. Agric. Water Manag. 35, 147-165.

Soil Survey Staff 1999 Soil Taxonomy. A basic system of soil classification for making and interpreting soil surveys. $2^{\text {nd }}$ Edition. USDA Natural Resources Conservation Service Agricultural Handbook 436. Washington DC.

Sumner M E and Stewart B A 1992 Soil crusting: Chemical and Physical processes. Advances in Soil Science, Lewis Pub., Boca Raton, 372 p.

Tedeschi A, Beltrán A and Aragüés R 2001 Irrigation management and Hydrosalinity balance in a semi-arid area of the middle Ebro river basin (Spain). Agric. Water Manag. 49, 31-50. 


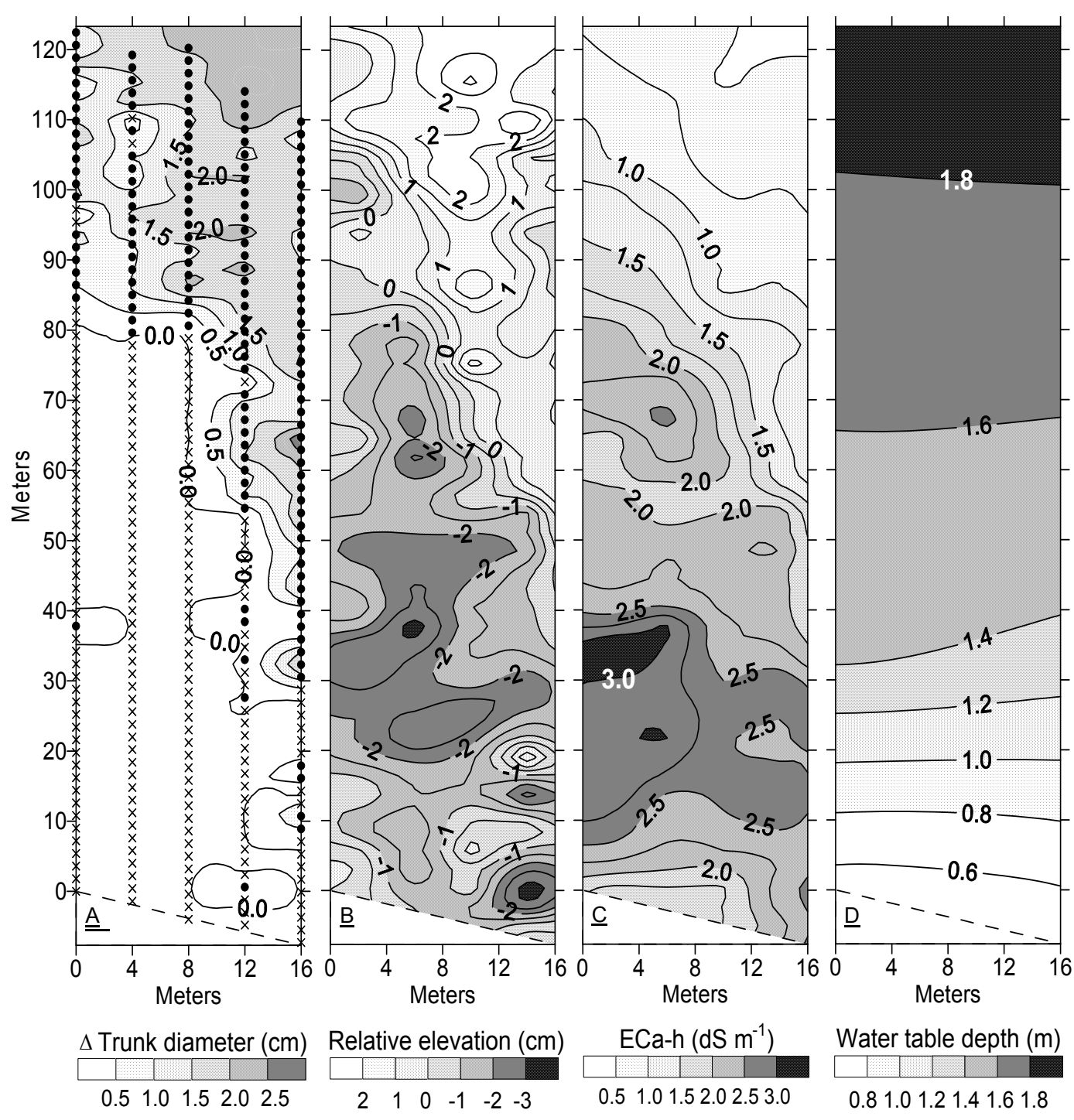

Figure 1. Contour maps of the $125 \times 16 \mathrm{~m}$ study field: (A) one-year growth trunk diameter of olives ( $\Delta$ Trunk diameter, $\mathrm{cm} ; \times=$ dead trees; $\bullet=$ living trees); (B) relative ground elevation over the mean (Relative elevation, $\mathrm{cm}$ ); (C) apparent soil electrical conductivity measured with the EM38 in its horizontal-dipole position (ECa-h, $\mathrm{dS} \mathrm{m}^{-1}$ ); (D) depth of the water table from the soil surface (Water table depth, m). 


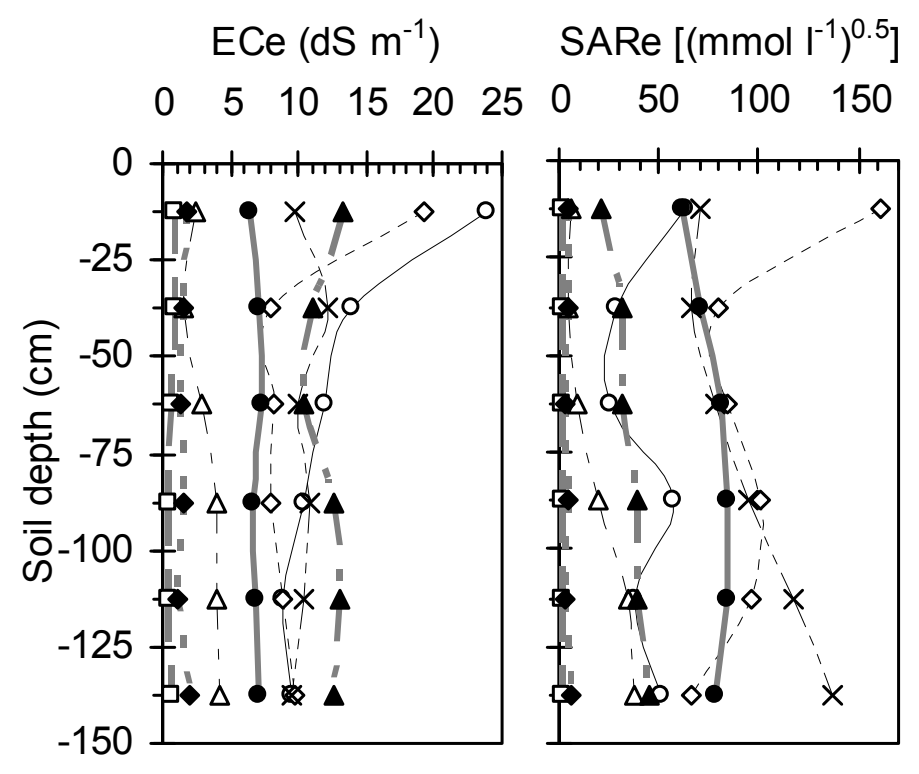

Figure 2. Soil salinity (ECe) and sodicity (SARe) profiles measured in June 1999 in eight points covering the entire study field and the full range of EM38 readings. 

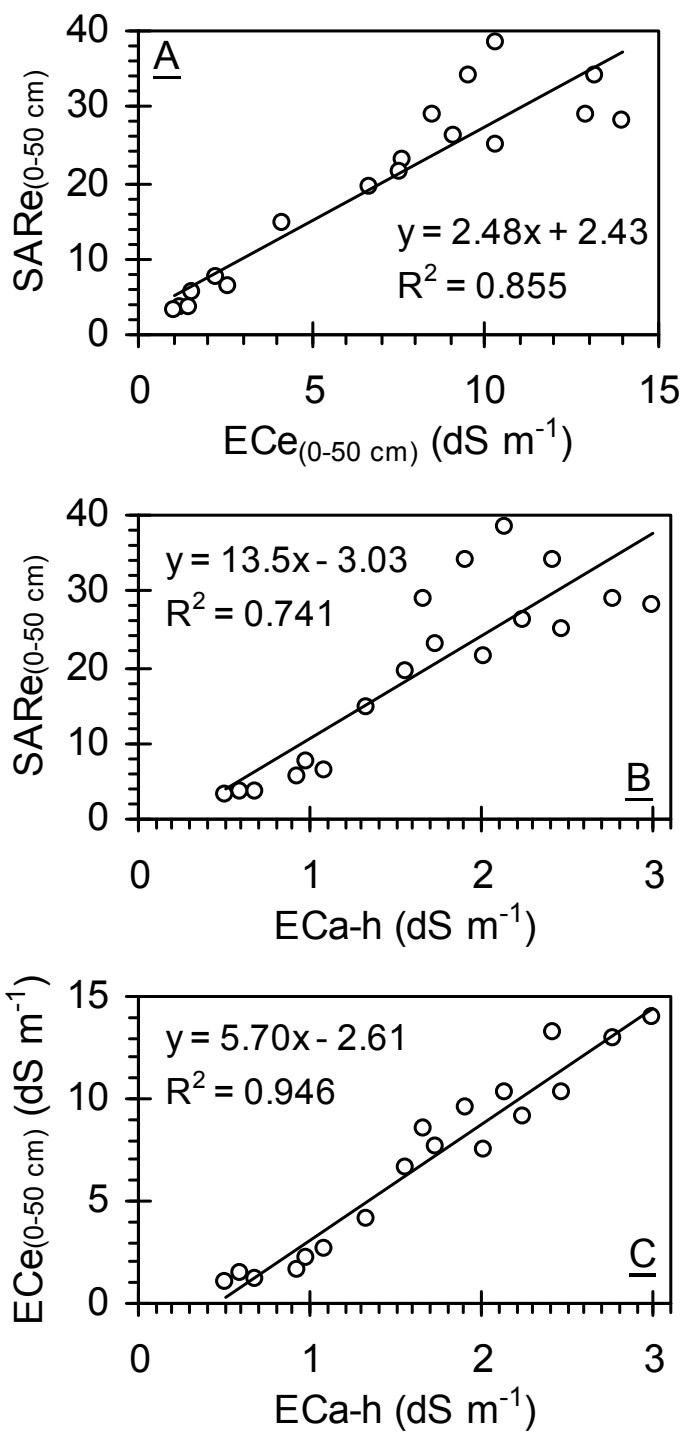

Figure 3. Linear regression equations of (A) SARe on ECe, (B) SARe on ECa-h, and (C) ECe on ECa-h obtained from eighteen soil samples (ECe and SARe) and EM38 readings (ECa-h) taken on September 2000 in the entire study field and the full range of EM38 readings. 


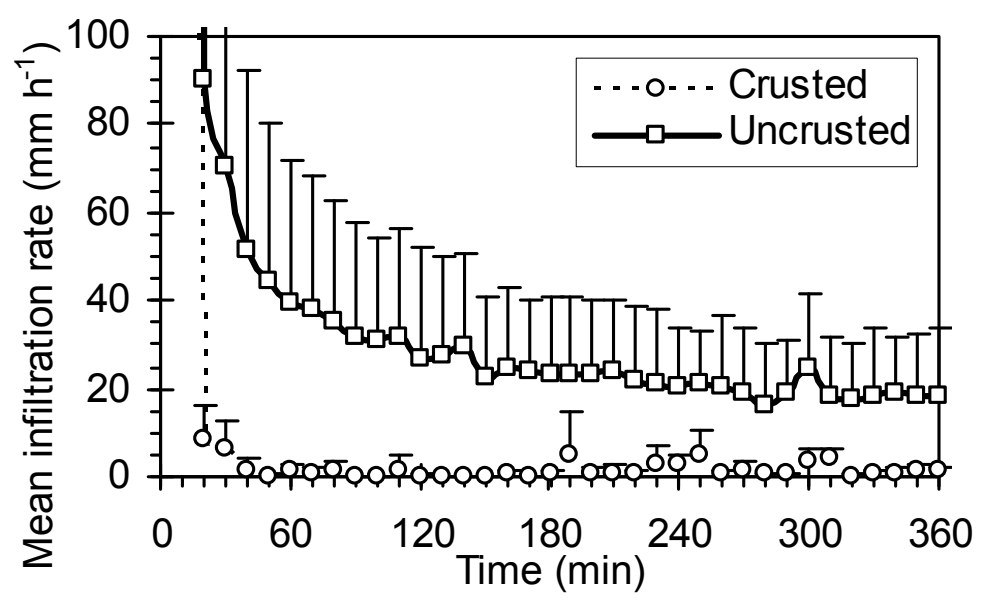

Figure 4. Mean infiltration rate of five measurements taken in September 1999 along the Y direction of the study field in crusted and uncrusted (i.e., the top $2 \mathrm{~cm}$ of soil were removed) soils. The vertical bars represent one standard deviation of the mean. 


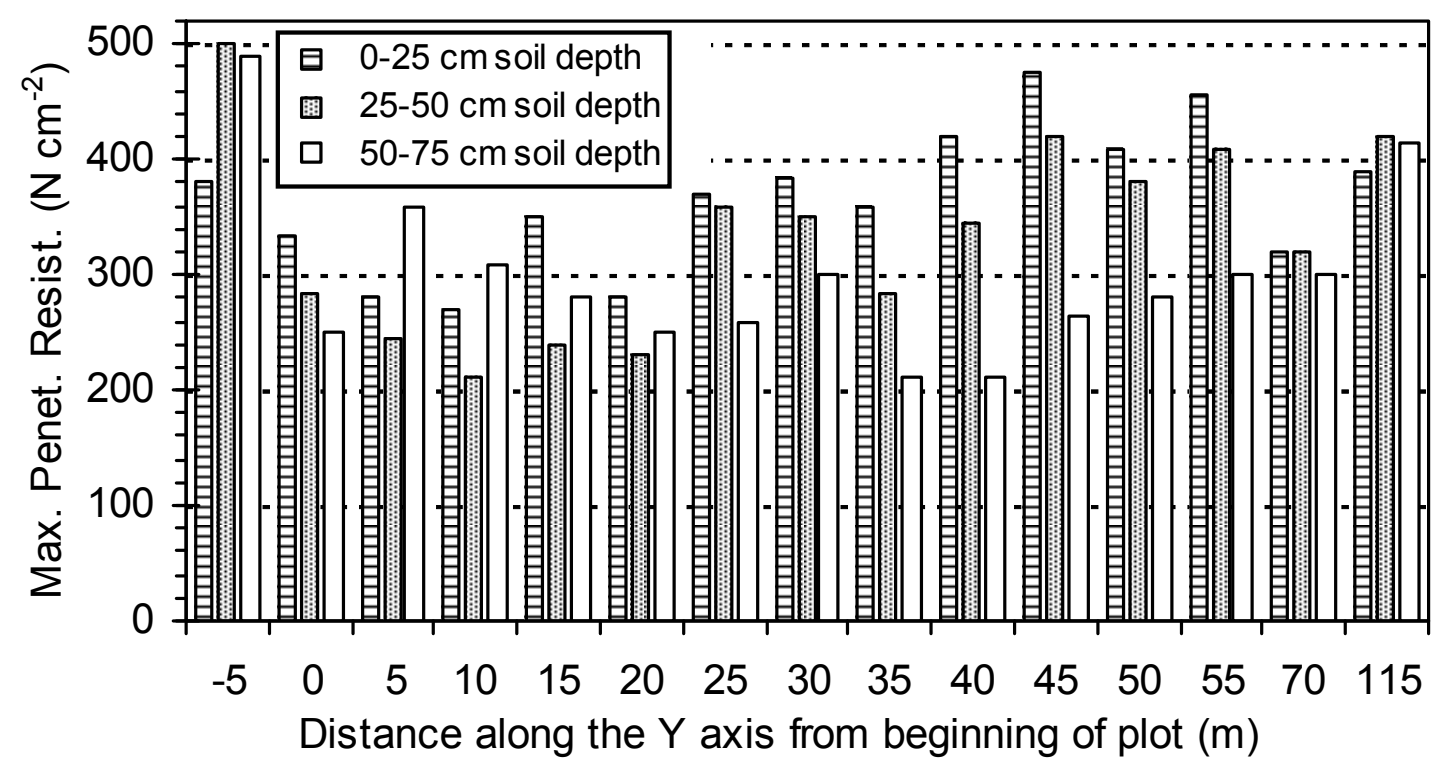

Figure 5. Maximum penetration resistance measured with a soil penetrograph at three soil depths in fifteen points along the $\mathrm{Y}$ direction of the study field. 

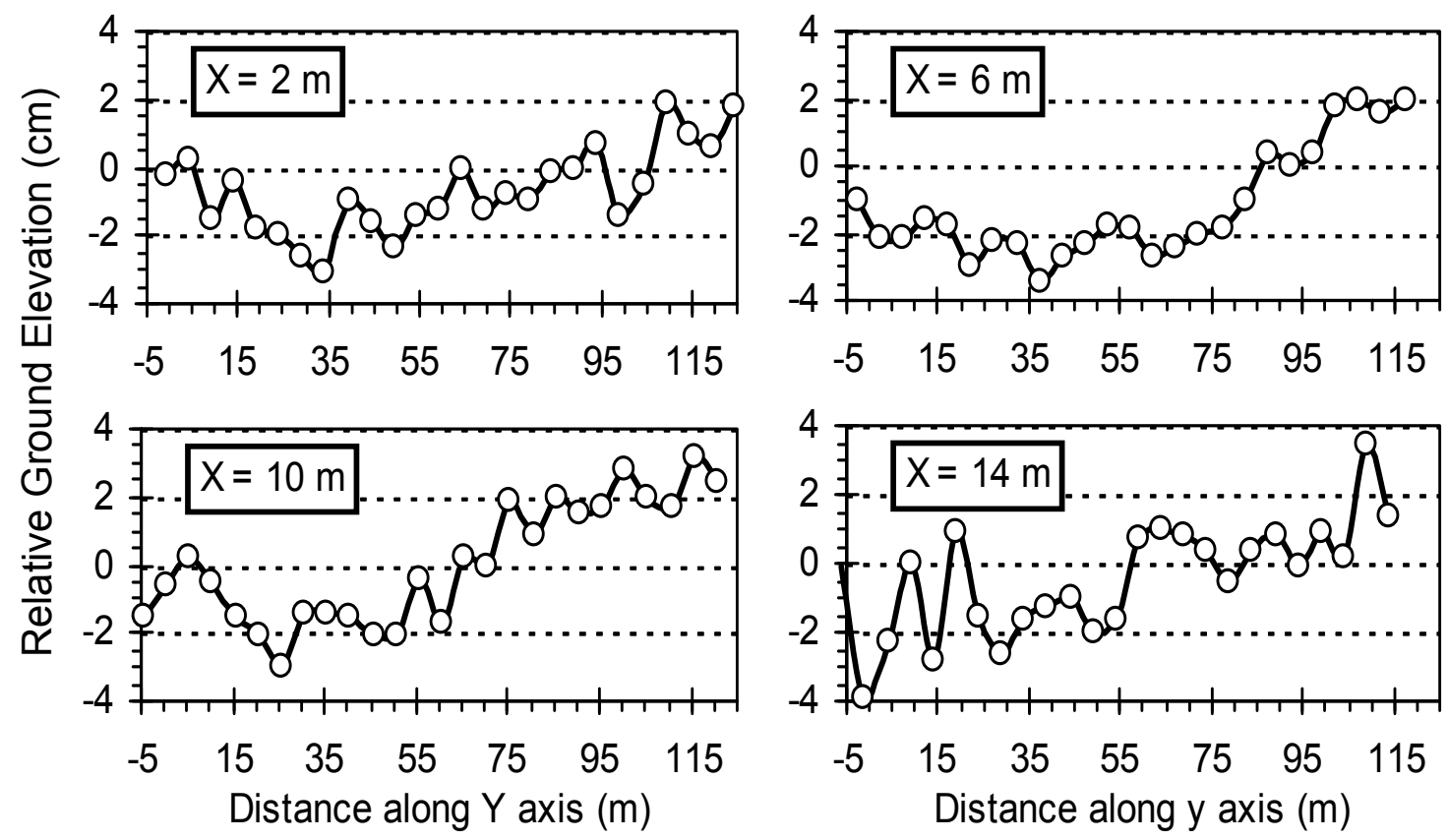

Figure 6. Relative ground elevation (RGE: $\mathrm{cm}$ above or below the mean ground elevation) measured in four transects $(\mathrm{X}=2,6,10$ and $14 \mathrm{~m})$ at $5 \mathrm{~m}$ distances along the $\mathrm{Y}$ axis of the study field. 

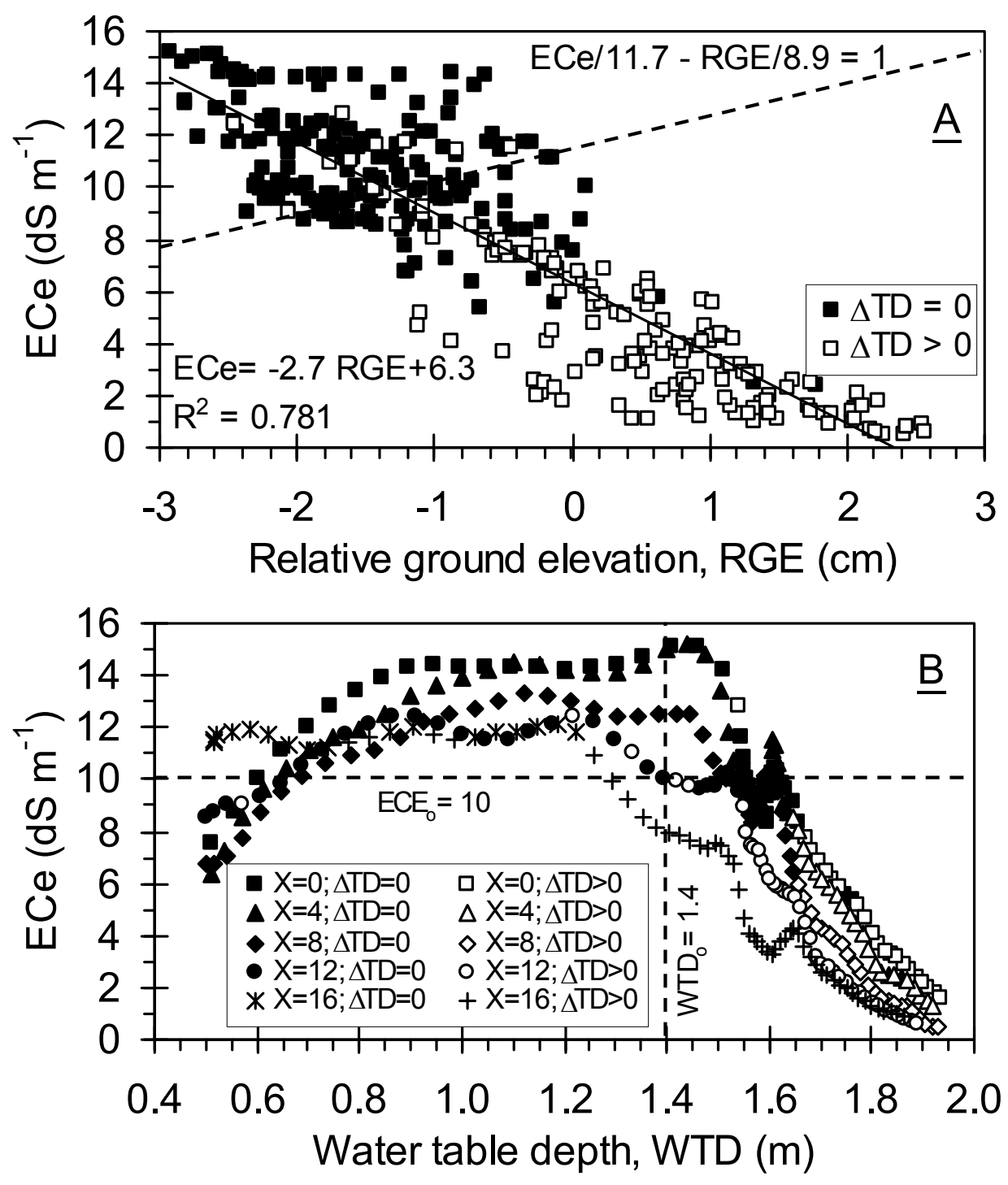

Figure 7. Relationships between soil salinity (ECe) and (A) relative ground elevation (RGE) and (B) average water table depths at the five olive's tree lines ( $\mathrm{X}=0$ to $16 \mathrm{~m})$. The regions of living $(\Delta \mathrm{TD}>0$; white symbols $)$ and dead $(\Delta \mathrm{TD}=0$; black symbols $)$ olive trees delimited by the regression models are also shown. 

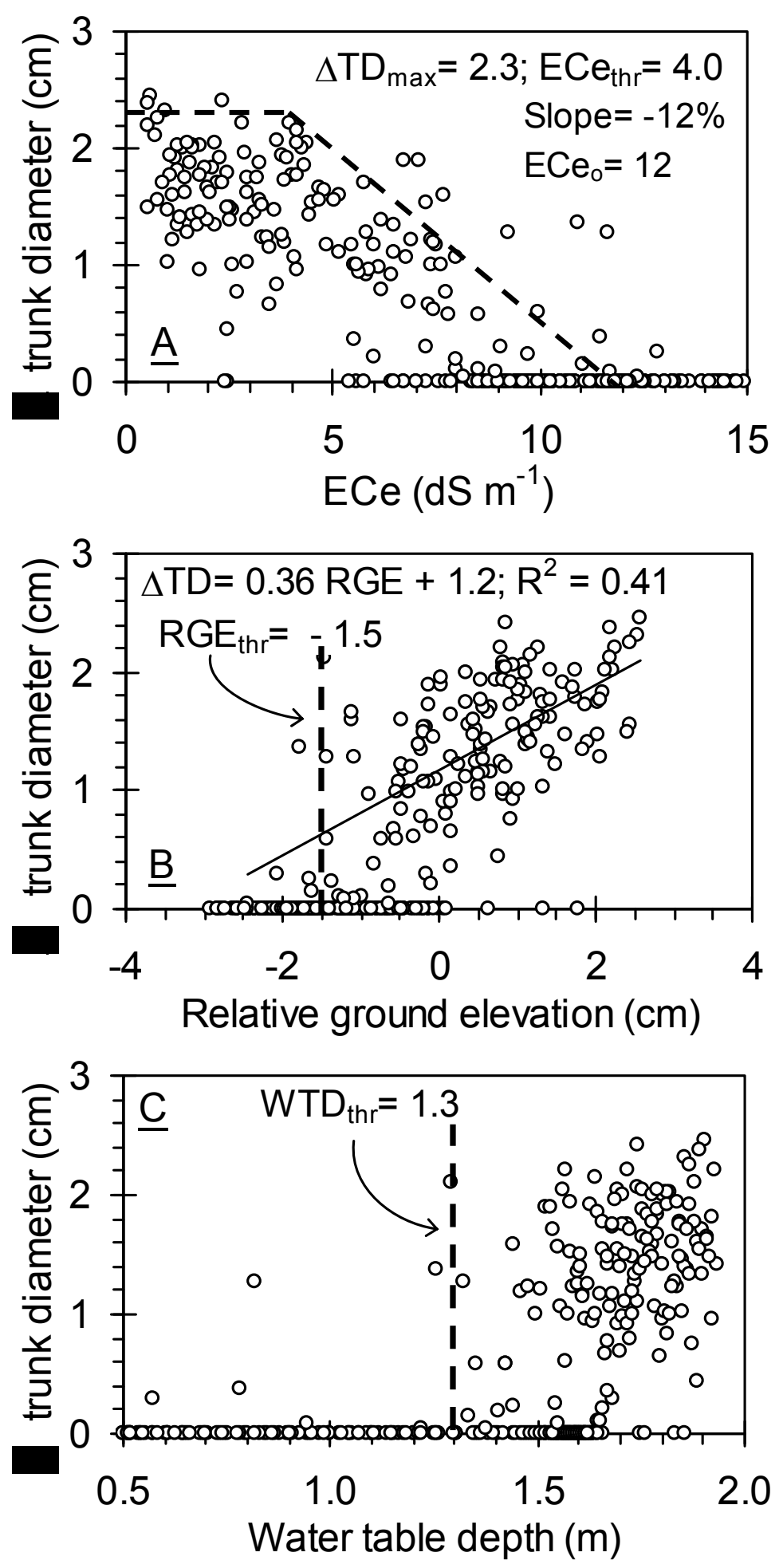

Figure 8. Relationships between the one-year growth trunk diameter ( $\Delta$ trunk diameter, $\Delta \mathrm{TD})$ of the olive's trees and (A) soil salinity (ECe), (B) relative ground elevation (RGE), and (C) water table depth (WTD). The $\triangle \mathrm{TD}-\mathrm{RGE}$ regression was obtained without the $\Delta \mathrm{TD}=0$ observations. The dotted lines are eye-fitting estimates of ECe, RGE and WTD thresholds. 


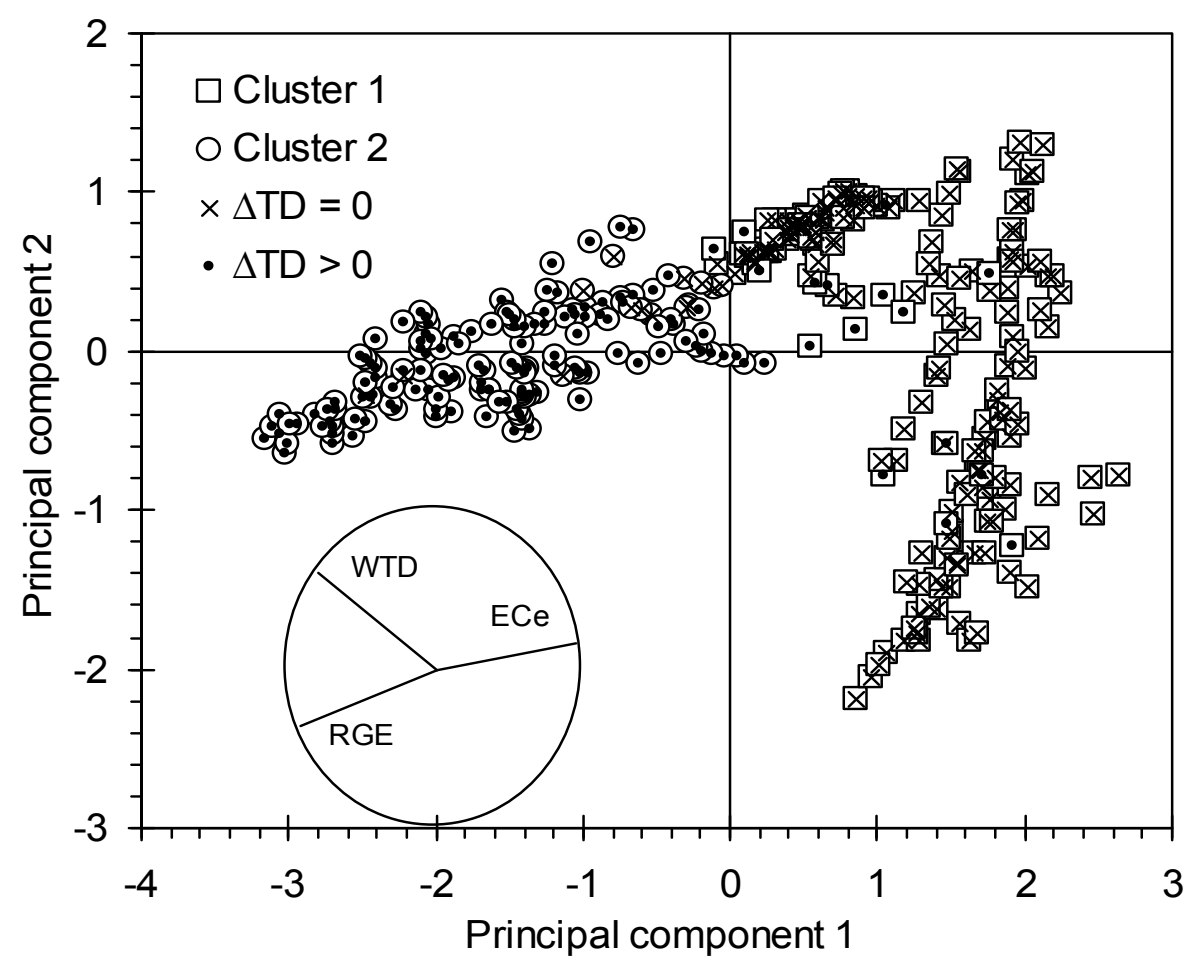

Figure 9. Scatter plot of the observations on the plane of the two first principal components of soil salinity (ECe), water table depth (WTD) and relative ground elevation (RGE). The two clusters delineated with the observations are presented, along with the indication of alive $(\triangle T D>0)$ or death $(\Delta \mathrm{TD}=0)$ trees. The projections of the explanatory variables on the plane are also shown. 

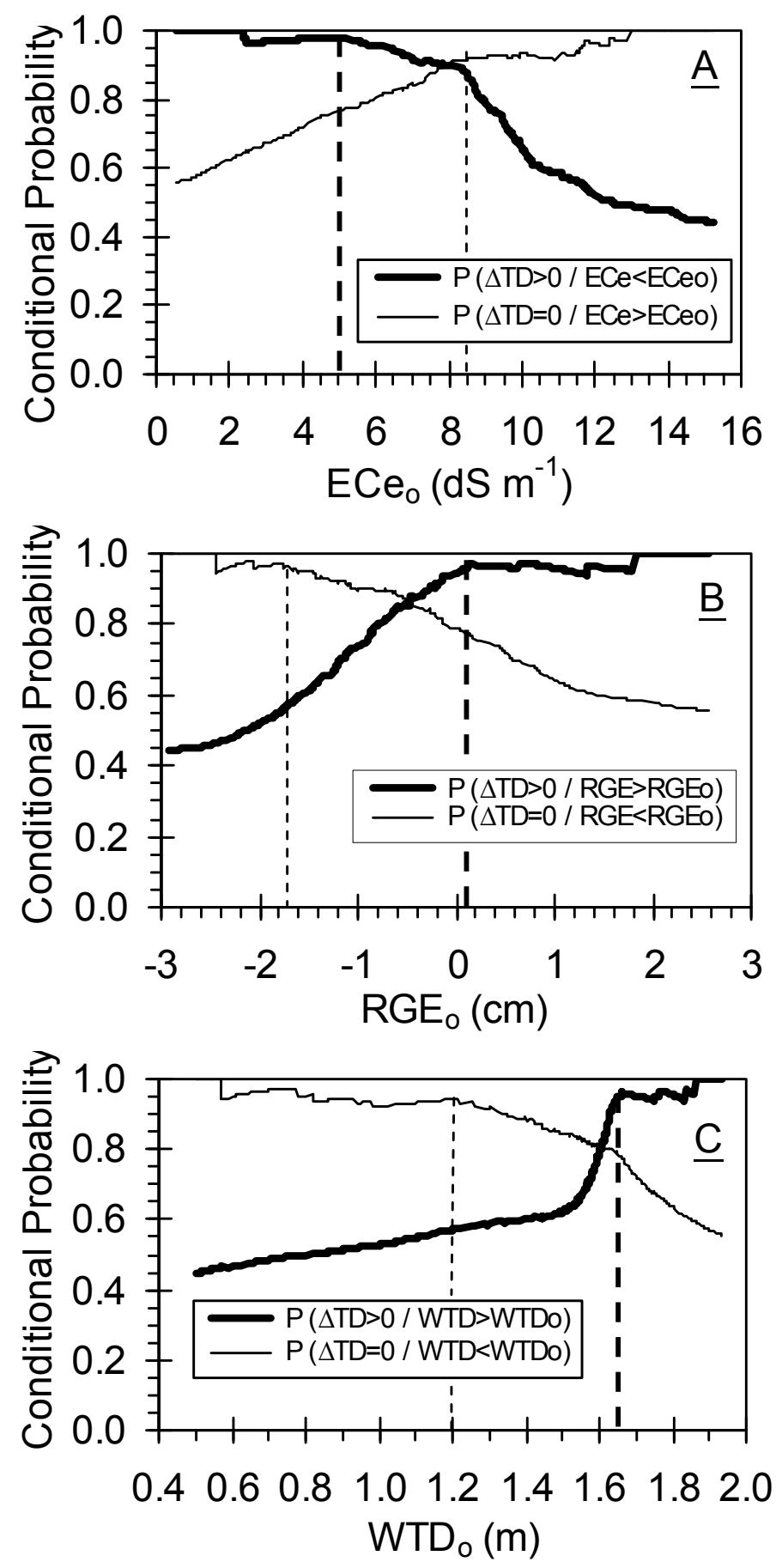

Figure 10. Conditional probabilities for a tree to survive $(\Delta \mathrm{TD}>0)$ or die $((\Delta \mathrm{TD}=0)$ provided that the explanatory variables (ECe, RGE, WTD) are below or above certain threshold values $\left(\mathrm{ECe}_{\mathrm{o}}\right.$, $\mathrm{RGE}_{0}, \mathrm{WTD}_{\mathrm{o}}$, respectively). 